\title{
Communicational ambidexterity as a new capability to manage social media communication within organizations
}

\author{
Jimmy Huang \\ Warwick Business School, The University of Warwick, Coventry, CV4 7AL, U.K. \\ Jimmy.haung@wbs.ac.uk \\ João Baptista \\ Warwick Business School, The University of Warwick, Coventry, CV4 7AL, U.K. \\ J.Baptista@wbs.ac.uk \\ Sue Newell \\ School of Business, Management and Economics, University of Sussex, Brighton, BN1 9RH \\ Sue.Newell@sussex.ac.uk
}

\begin{abstract}
Central to our inquiry is a pressing issue for many organizations today of how to manage and accommodate conflicting demands in managing internal communication inherent to the adoption of more open communication environments supported by social media. Drawing on ambidexterity theory we investigate and analyse the challenges and capabilities necessary to effectively manage two distinct types of internal communication 1) organizationally-produced content and 2) usergenerated content. We propose and unpack the notion of communicational ambidexterity to theorize the capabilities that enable organizations to accommodate and efficiently manage these two potentially conflicting modes of communication within organizations.
\end{abstract}

Keywords: Ambidexterity, communicational ambidexterity, internal communication, social media.

\section{Introduction}

Rapid diffusion of social media is (re)shaping the landscape of communication in contemporary society (Boudreau and Lakhani, 2013; Hanna et al., 2011; Pitt and Berthon, 2011). While prior studies have illustrated various benefits, such as fostering engagement, participation, knowledge reuse and collective innovation (Kaplan and Haenlein, 2010; Majchrzak, et al., 2013; Skågeby, 2010), social media's impacts and potential implications remain a fertile research ground for IS researchers (Jarvenpaa and Majchrzak, 2010).

In current conceptualizations of social media, two emerging trends are apparent. Firstly, increasing attention is being paid to the potential negative effects and unanticipated consequences of social media (e.g. Champoux, et al., 2012; Hildebrand, et al., 2013), revealing that social media is far from being a technological panacea for addressing communication and social interaction problems (Cook, 2008; Goh et al., 2013; Granados and Gupta, 2013). However, how to exploit the potential of social media without unleashing its negative potential remains relatively unexplored. Secondly, studies increasingly consider social media-related phenomena at the community and societal levels (e.g. Miller and Tucker, 2013; Oh, et al., 2013), for example, considering how organizations interact with their external stakeholders using social media (e.g. Fournier and Avery, 2011; Oestreicher-Singer and Zalmanson, 2013). However, the adaptive use of social media within an organizational context and its impacts on the process and dynamics of communication are relatively undertheorized (Majchrzak, et al., 2013). 
To enrich our understanding and address both of these issues, we conduct an exploratory, indepth, longitudinal case study at a multi-national company, which we call Tudor Rose Telecommunications (TRT). Core to our inquiry is to make sense of a managerial challenge faced by TRT, which is how to "allow for effective mobile working (i.e., virtual) and at the same time help employees feel a sense of belonging to the firm?" This question surfaces not just an issue of how to establish new mobile work practices, but also how to create a communication environment to facilitate mobile working which retains an effective sense of belonging to the organization (despite the reduction in face-to-face communication). Using social media is presented as one solution to this problem, because this allows users to contribute and discuss ideas even when not physically present (McGriff, 2012; Subramaniam, et al., 2013), and can thus help to create a sense of belonging for mobile workers (Haslam, et al., 2003). However, social media can also produce conflicting views and opinions that might over-shadow the message the organization wants to convey to all its employees. The practical problem thus raises an interesting theoretical question - how does an organization accommodate conflicting perspectives in a more open communication environment while still preserving a sense that there is a coherent organizational message? In order to address this research question, we consider the role social media plays in increasing the visibility of conflicting perspectives and we consider what capabilities, mechanisms and governance structure surrounding social media can help to address the challenge of allowing many voices while still retaining a coherent organizational message.

Our findings demonstrate that social media can be effectively used in a way that reconciles these conflicting challenges in internal communication. In conceptualizing our findings, we draw on the theory of ambidexterity (Cao, et al., 2009; Gibson and Birkinshaw, 2004) to show how a distinctive capability, which we call "communicational ambidexterity" was developed in the case organization. Our contributions are threefold. In addition to enriching our understanding of how social media can enhance internal communication even while it allows for conflicting ideas to be more evident, we extend the existing intellectual landscape by theorizing a new type of ambidexterity and its enabling mechanisms. By so doing, we make our third contribution, which is to illustrate the role of social media in the accomplishment of communicational ambidexterity.

The paper is structured as follows. We first introduce the current debates and perspectives that are fundamental in theorizing communicational ambidexterity. Second, we outline our methodological considerations and research processes that depict the rationale behind our research design and data analysis processes. Third, to illustrate our case findings, we present a narrative, which outlines the communication challenges encountered by TRT and its journey in addressing them. Fourth, in the Analysis and Discussion section, we identify the key characteristics of communicational ambidexterity and outline how various enabling mechanisms function to support this capability. We conclude by identifying the theoretical implications of our findings and areas where future research efforts would be useful.

\section{Current Debates and Perspectives}

Central to the theoretical contribution of this paper is our proposed notion of "communicational ambidexterity". We define communicational ambidexterity as the capability to simultaneously address different and often conflicting communication needs that exist in an organization's internal communication, and achieve complementarity between these. This notion is developed based on an iterative process between the reflection of relevant literature and our data analysis. In this section, we outline the key theoretical 
building blocks that we draw on, namely: conflicting communication modes; the capability of ambidexterity; and its enabling mechanisms.

\section{Conflicting Communication Modes}

To unpack the above research question, it is essential to understand the challenges associated with using competing and potentially conflicting communication modes, as happens when an organization introduces social media to drive mobility and support a more open internal communication environment. To do so, we draw on the distinction between "univocality" and "multivocality" (Balmer, 2001; Huang, et al., 2013) as a conceptual basis. Compared with the institutional, formal, centralized and often top-down type of communication characterised as univocality, a distinct type of communication characterised as multivocality refers to usercentric, distributed, informal and often participative modes of communication.

The growing use of social media to support internal communication widens participation (Denyer, et al., 2013) and interactive dialogue (Miles and Mangold, 2014), which then increases the multivocality of the internal communication environment. However a more multivocal communication environment also means that sources and content is more diverse. So instead of being controlled and formally published by the organization as expected in a univocal environment, multivocality supports and encourages user-generated content. Despite the gains of a multivocal environment in development of social identity (Haslam, et al., 2003) and encouraging participation and diversity (McGriff, 2012) there are real challenges in managing it concurrently with univocality.

Cooren, et al. (2011, p. 1149) highlight the important role of communication as part of the fabric that "constitutes organizing and organization". In multivocal environments communication is open and distributed and generated by its users - user-generated content (UGC) (Goh, et al., 2013). This contrasts with the univocal model, which is centred on content generated centrally by a small team under the guidance of senior management, termed by us as organization-published content (OPC). One of the effects of introducing social media within organizations is that it supports both higher reach in disseminating OPC (Huang, et al., 2013) and eases the creation and sharing of UGC (Goh, et al., 2013; Razmerita, et al., 2014). Given its institutional and constitutive significance, OPC is often protected as one of the most crucial managerial resources and sources of power (Taylor, 2011). Therefore, introducing multivocal modes of communication to enable UGC will upset established patterns of communication and power relationships previously reinforced by a more centralised control system (Duane and Finnegan, 2003). What particularly interests us is whether multivocality and UGC can exist alongside and potentially complement univocality and OPC in internal communication, despite the obvious tensions between these two modes of communication. In other words, is it possible for an organization to become ambidextrous in its internal communication by addressing the challenges associated with being simultaneously multi-vocal and univocal? And how can an organization develop complementarity between these two modes of communication? To progress our inquiry, we reflect and draw on the theory of ambidexterity.

\section{The Capability of Ambidexterity}

Central to addressing conflicting managerial challenges is the requirement for simultaneously developing solutions for different problems that are often contradictory in their existence and functioning (Andriopoulos and Lewis, 2009; Tushman and O'Reilly, 1996). For instance, Adler, et al. (1999) show that it can be highly problematic for organizations to be efficient and at the same time remain flexible. This is because these two capabilities - efficiency and 
flexibility - function in rather distinctive manners and are each supported by specific organizational settings. Thus, these two capabilities often represent trade-offs that organizations need to manage. Research shows that firms that are able to simultaneously achieve efficiency and flexibility can achieve exceptional organizational performance, and are described as "being ambidextrous" (Duncan, 1976; Tushman and O'Reilly, 1996).

Research on ambidexterity is found across a number of different areas. For example, Bartlett and Ghoshal (1988) illustrate how ambidextrous organizations are able to concurrently ensure global integration and local responsiveness. In conceptualizing organizational learning, March (1991) outlined the paradoxical relationship between knowledge exploration and knowledge exploitation and the need to ensure an organization's overall variability in learning in order to maintain competitiveness. Later accounts (e.g. Andriopoulos and Lewis, 2009; Cao, et al., 2009; He and Wong, 2004) have focused on how exploring new business opportunities can work side-by-side with the exploitation of existing niches. In IS research, ambidexterity has been applied to a variety of different contexts, including deploying conflicting methodologies in systems development (Tiwana, 2010; Vinekar, et al., 2006), balancing strategic choices between customized and packaged software products (Napier, et al., 2011) and concurrently fostering sustainability with profitability in a telecommunication company ( $\mathrm{Du}$, et al., 2013). Despite these variations in the focus of ambidexterity research, there is much agreement about what supports ambidexterity. This draws on Gibson and Birkinshaw's (2004) distinction between structural and contextual mechanisms that we discuss next.

\section{Enabling Mechanisms of Ambidexterity}

To synthesize a rather diverse range of accounts previously published, in particular those based on the intellectual traditions of Duncan (1967) and March (1991), Gibson and Birkinshaw (2004) distinguish between structural and contextual mechanisms that support ambidexterity. First, in terms of structural mechanisms, the notion of dual structure, originating from Duncan (1967), suggests that ambidexterity is fostered by creating distinct organizational functions or units, each with the ability to address different managerial challenges (Tushman and O'Reilly, 1996). For instance, while R\&D is structured to tolerate the uncertainty commonly encountered in innovation, manufacturing units are often organized to maximize efficiency by minimizing coordinating costs and reducing ambiguity (Adler, et al., 1999; Grant, 1996). However, despite the usefulness of structural mechanisms, Gibson and Birkinshaw (2004) suggest that these alone are not sufficient and propose that contextual mechanisms are also needed to support "the behavioral capacity to simultaneously demonstrate alignment and adaptability across an entire business unit" (Gibson and Birkinshaw, 2004; p. 209). Gibson and Birkinshaw indicate that alignment refers to the level of coherence between an organization's strategic goals and activities that are performed to actualize these goals. Adaptability is an organization's collective ability to effectively adjust, mobilize and reconfigure internal resources, activities and processes to address the changing demands from its external environment (Ghoshal and Bartlett, 1994). Alignment is facilitated by mechanisms, such as collective trust and organizational support, characterized as "social context". Adaptability is enabled by an organization's ability to introduce and exercise "discipline" of its workforce and to "stretch" them to unleash the workforce's potential to meet exceptional demands, which relates to "performance management".

Later accounts, such as that developed by Jansen, et al. (2009), also reinforce Gibson and Birkinshaw's (2004) view that dual structures alone are far from being sufficient for achieving ambidexterity. This is because dual structures do not automatically address the 
need to "mobilize, coordinate, and integrate dispersed contradictory efforts, and to allocate, reallocate, combine, and recombine resources and assets across dispersed exploratory and exploitative units" (Jansen, et al., 2009, p. 806). Thus, it is clear that structural mechanisms need to be reinforced with contextual, human-centric mechanisms, such as individual characteristics, abilities and roles, and leadership (e.g. Raisch, et al., 2008). For instance, Smith and Tushman (2005) and Kang and Snell (2009) both highlight the importance of individuals' cognitive capacities in acquiring, processing and making sense of paradoxical situations and organizational settings, which facilitate and prohibit the development of such capacities. Similar findings are reported by Beckman (2006), who outlines the importance of diversity in top management team's experience.

\section{Theorizing Ambidexterity in Organizational Communication}

Based on this review, Figure 1 synthesizes the key conceptual elements of ambidexterity. Essentially, this figure consists of three components. The first component is the enabling mechanisms, which could be structural, such as partitioning and switching (Adler, et al., 1999), or contextual, such as stretch, discipline, trust and support (Gibson and Birkinshaw, 2004), or a combination of both (Jansen, et al., 2009; Tiwana, 2010). The second component refers to the two distinctive activities of ambidexterity, which range from knowledge exploration and exploitation (March, 1991), efficiency and flexibility (Adler, et al., 1999) to adaptability and alignment (Gibson and Birkinshaw, 2004). It is vital to note that the two activities often exist in tension, due to differences in their orientations and functioning. The third component represents the distinctive organizational performance contributed by ambidexterity.

\section{Figure 1. An integrative framework of ambidexterity and its enabling mechanisms}

\section{<Insert Figure 1 about here>}

We use the concepts presented in Figure 1 to develop the notion of "communicational ambidexterity" in the context of using social media to support UGC and a multivocal communication environment while simultaneously supporting OPC and a univocal message. As suggested by accounts such as Jansen, et al. (2009), Tiwana (2010) and Napier, et al. (2011), the theorization of ambidexterity needs to take into account more than one set of enabling mechanisms in developing ambidexterity as an organizational capability. This point is particularly relevant to our quest to theorize communicational ambidexterity. Given the importance of social media in multivocality and univocality (Huang, et al., 2013), we reflect on the current theoretical progression related to social media in organizations by elaborating three distinctive yet interrelated foci that we believe are useful for our theorization. The first area focuses on different managerial benefits and potentials afforded by social media. In addition to enhancing collaboration, social interaction and participation (Denyer, et al., 2013; Haefliger, et al., 2011; Wu, et al., 2013), these benefits are centered around knowledge management, in particular in sharing and documenting dispersed organizational knowledge (e.g. Majchrzak, et al., 2013; Yuan, et al., 2013). As elaborated by Razmerita, et al. (2014), an organization will rely on different social media tools to fulfill different tasks. Hence, when considering adopting different social media tools, it is essential to consider the totality rather than each tool in isolation. This has brought out our concern about how an organization's communication platform, in particular when incorporating social media, can relate to communicational ambidexterity. The second area emphasizes different managerial issues and challenges related to the use of social media, such as protection of intellectual property (Väyrynen, et al., 2013), security and privacy (Andriole, 2010) and employee motivation 
(Agerdal-Hjermind, 2014). A growing number of papers have pointed out that social media can be a double-edge sword. For instance, Miles and Mangold (2014) indicate that social media might help organizations access untapped internal resources, but can also become a 'time bomb' for internal communication. Furthermore, Hall and Lewis (2014) point out that social media might provide another channel for workplace bullying, unless suitable policy and governance structures are developed. These accounts have highlighted the need to emphasize more on the governance of social media, and provided a useful pointer for our theorization. The third area focuses on the dynamic interplay between social media and organizational processes, for instance in relation to the maintenance of identity (OmilionHodges and Baker, 2014) and rhetorical practice (Huang, et al., 2013). Furthermore, Denyer, et al. (2011) elaborate on the role of organizational culture, in particular nurturing an open and collaborative culture, to capitalize on social media. These prior accounts of social media point to some mechanisms that might be relevant to producing communicational ambidexterity, such as structurally differentiating different tools for different purposes, establishing governance structures to support both OPC and UGC and developing a collaborative culture. However, the specifics of these mechanisms in simultaneously supporting univocality and multivocality needs further examination and this is the focus of our case analysis.

Summing up, while the current literature suggests tensions between univocality (as an OPC model) and multivocality (as a UGC model) we suggest that it is possible for organizations to develop these two communication modes simultaneously over time. Responding to calls for more research on communication as the constitutive process of organizing and organization (see, for example, Cooren, et al., 2011; Spee and Jarzabkowski, 2011; Taylor, 2011), our research aims to empirically explore this suggestion. The aim of our research is therefore to consider how organizations can simultaneously operate as univocal (OPC) and multivocal $(U G C)$ as they expand the use of social media as a primary and wide scale communication platform.

\section{Methods}

This study is part of an on-going research project aimed at examining the development, usage and governance of social media for internal communication in large multi-national organizations operating in high velocity industries, such as professional services, finance and telecommunications (Eisenhardt and Martin, 2000). The research design involves an in-depth, interpretive and longitudinal case study approach (Pan and Tan, 2011; Walsham, 1995). The strengths of this approach in exploring research phenomena that are highly situated and context dependent in their sense-making, are well documented (Pan and Tan, 2011). To achieve our objective of documenting and theorizing communicational ambidexterity we adopt the perspectives and concepts outlined in the previous section as "sensitizing devices" to guide data collection and analysis and eventual theorization of this phenomena (Klein and Myers, 1999).

One requirement emerging from the literature review is the need to select an organisation that has extensive and use of social media as a communication platform to support internal communication. For this reason we chose an organisation that was an early adopter of web technology to support large-scale mobile work, which highlighted an important topic of research that was both relevant for the company and theoretically insightful for us, of how social media can be used to simultaneously drive mobility and retain a sense of belonging within the work force. Realising the practical significance of the study was an important 
driving force for the research, which allowed us to stay engaged with the company for a long period of time and also extract deeper insights from our interactions with the organization.

\section{Data Collection}

Data collection at TRT started in 2007, and our research effort to continuously document the case organization's journey in using social media is ongoing. The data collection has been carried out to fulfil several distinctive yet interrelated purposes. First, we collected data that can be used to sketch the case organization's overall communication landscape. This includes the functionalities, general usage and governance of social media in the case organization. Second, we collected data that characterize the promoting and opposing forces in shaping the dynamics of its internal communication. Third, we collected reflexive insights that represented individual's experiences. Here, we did not limit data collection to just the actual experiences of using social media, but also considered the experiences of various organizational members whose roles are related to the management of social media and internal communication.

A number of different data collection methods, including interviewing, documentation, informal dialogue and onsite observation were used. In total, 65 semi-structured interviews have been conducted since March 2006 as part of an ongoing working relationship with an industry group called the Digital Workplace Group (DWG). DWG benchmarked TRT's intranet annually over a number of years and we followed this process while collecting our own notes in the field. The first interaction with TRT was in 2006, and then annually until 2011. Each year we conducted 10 to 12 interviews, following in part a core group of stakeholders (all the core team involved in managing digital media within TRT) but each year adding new people to the list of interviewees (other key stakeholders such as local publishers, brand managers, operations and general users). Since 2011 we have followed the events at TRT through regularly interviews with the core group of stakeholders. Each interview lasted between 60 and 90 minutes. Each interview consisted of two parts. The first part aimed to acquire data that were related to each interviewee's personal background, job responsibilities, general usage pattern of social media and their observation of the evolutionary journey of social media at TRT. The second part aimed to capture insights related to interviewee's personal experience in using social media for internal communication and their perceptions of promoting and opposing forces encountered at TRT. Over 300 screenshots, such as webpages and blog posts from the case organization's intranet, were collected. Internal documentations, including governance and strategy documents, social media policy and steering group meeting minutes, were reviewed and incorporated into the analysis. Research notes were taken during each site visit. The aim was to ensure that relevant issues emerged from on-site observation and that informal discussions were effectively captured.

\section{Data Analysis}

Given the exploratory nature of the research, we have incorporated the technique of continuous iteration between the relevant theoretical perspectives, collected data and emerging findings and relevant literature (Eisenhardt, 1989; Orlikowski, 1993). Conceptual elements reviewed in the previous section played the role of a "rake", a metaphor originally used by Carney (1972). According to Carney this metaphor is useful because, "a new rake is not needed for each new job of raking" (ibid., p. 6), so that there is no need to constantly reinvent the wheel, given that suitable conceptual tools are already available to be utilized and built on. Moreover, "the rake does not unconsciously select only those objects which are of interest to us, or which suit our views" (ibid., p. 6-7). By utilizing some of these existing 
concepts systematically, validity and reliability can be achieved by paying similar amounts of attention to all collected data.

Our data analysis approach contained four interconnected steps, including "summarizing", "clustering", "displaying" and "comparing" the data (Easterby-Smith, et al., 1991). Key points embedded in each interview transcript, document and field note were summarized by two of the authors. These steps were first carried out during January and March of 2013. By applying the three trade-offs in communication and the distinction between structural and contextual mechanisms for ambidexterity (Gibson and Birkinshaw, 2004), we were able to cluster the data collected from each source into different themes, and display them with sufficient conceptual distinction identified. Even though the steps of summarizing, clustering and displaying were accomplished, it did not warrant the articulation of interrelationships between the key conceptual elements remaining. Through the technique of comparing the analyzed data, we then searched specifically for empirical insights, which could help us to identify and establish the interrelationships, in this case how structural and contextual mechanisms help to develop communicational ambidexterity.

\section{Case Findings}

To set the context of our case findings, we chronologically present key events and communication challenges (see Figure 2). We use a "rope" as a metaphor to symbolize how impacts created by events and challenges are continuous and interrelated. We start our narrative with TRT's "Mobile Working Initiative".

\section{Figure 2. A chronological view of key events and communication challenges}

\section{$<$ Insert Figure 2 about here $>$}

\section{Becoming a mobile working organization}

Starting in mid-2000s, an initiative to transform TRT's workforce into a mobile workforce, particularly focused on its 30,000 or so field engineers, was aimed at saving costs and better fulfilling customers' demands and enhancing employee productivity by cutting down travelling time. For instance, before mobile working, field engineers would go to their offices to download their daily work schedules, then travel to clients' premises. In addition, to addressing efficiency at the field level, another aim was to encourage and speed up effective management collaboration. As one of the interviewees from the Intranet Team stated:

\footnotetext{
"Around 2007 the people in our global part of the business came to us saying, you know, we've got this problem, we can't move quickly enough. If a customer asks us to do a tender we just are struggling to meet the deadline, never mind whether the quality of the tender is of any use or not. Because people are just too busy and they can't fly to wherever they needed to be for the project meeting."
}

To prepare for the mobile working initiative, the most challenging issue was to change managers' mindsets about how they perceived their roles. Several interviewees highlighted that there was a strong belief among many managers in the past that power came from the control of information. Based on this mindset, they were not particularly helpful in supporting and facilitating the sharing of information, which was crucial for mobile working. As the former manager of the Intranet Team noted: 
"A lot of managers had to change their behavior, to be more of a facilitating type of manager and one that encouraged people rather than just told people what to do. And a number of managers couldn't cope with that and left under sort of early release packages... I think the biggest problem, apart from field engineers before they had access, was a lot of middle managers just couldn't make that adjustment."

This strategic initiative thus had to deal with the need to transform the existing communication platform (i.e., the company intranet) in order to cater for more diverse and sometimes conflicting demands across the business. For instance, the intranet needed to provide the mobile workforce, now representing two-thirds of its total headcount, with tools to support collaboration and access required information to schedule and perform their tasks without "a lot of operational information that people were drowning in". TRT also needed to update the workforce on what was happening across the organization to increase engagement and a "sense of belonging" while employees reduced face-to-face contact as they moved towards a more mobile working model.

Another related challenge was to concurrently cater for different communication needs at global (corporate) and local (lines of business) levels. When recalling the situation back in 2007, one interviewee explained: "there is no formal framework for balancing global/local content, regional and local organizational sites and news feeds allowing access to localised content." To ensure that local information was provided and located a "few clicks away" from TRT's homepage, too many steps were needed. To address this issue the central team developed a new site architecture, by consulting stakeholders in different lines of business to obtain feedback and consensus. After several iterations, a new foundation for TRT's intranet was laid out in 2008. Even though the architecture of TRT's intranet has changed a few times subsequently, the approach to consult stakeholders, in particular users, continued. Also, the belief that "TRT's intranet is for everyone and owned by everyone" started to take root.

Another significant new feature was the creation of different governance models for the two main types of content on the intranet: one for that formally published by dedicated, trained communication specialists (i.e., OPC); the other published by users (i.e., UGC). Just for clarity, we are aware that UGC is used mainly in the context of the general public (e.g. Goh, et al., 2013) however in this study we refer to "users" as TRT staff.

\section{Organizational response to the growing use of $U G C$}

Over the duration of our involvement with TRT, social media became increasingly important as a communication tool within the organization. Several interviewees stated that it was now "the life-blood of the company" which is "alive and evolving". TRT's intranet had gradually become the primary channel of internal communication and the one with the highest reach across the organization. A significant milestone in TRT history was reached in 2009 when all the field engineers were provided with intranet access and this officially became the platform used to support the work of nearly 90,000 employees across 61 countries, deployed to allow the organisation to reduce office space by fully enabling remote work.

The growing importance of TRT's intranet as a central platform for work was accompanied by the growth of social media tools available on the intranet. Table 1 shows the main services available as either OPC or UGC channels, and outlines each service's function and general usage. OPC channels covered services that were managed with a high degree of central control. UGC channels refer to services enabled by social media technologies but used by 
regular employees of the company not specifically trained to be content producers or publishers and operating outside central control but with the obligation to respect shared guidance and standards on tone of voice and legal requirements.

\section{Table 1. Intranet services, functions, governance \& content management and usage description}

\section{<Insert Table 1 about here >}

The growing use of social media as a communication platform generated tensions and several challenges, which highlight the clear clash of needs between UGC and OPC, and pre-empt the need to develop internal capabilities to effectively manage these two distinct modes of communication. We now review some of the key challenges and mechanisms used to cope with the conflicting demands between these two modes of communication.

One of the initial challenges was senior managers' fears about loosing their ability to structure content and retain editorial control of what was being published. Adopting and embracing social media meant that any employee could start a blog or comment on a post without any moderation. As one of the interviewees from the Intranet Team explained:

"... fear of the unknown. 'Oh, if we do this people will let all this information about TRT out to the press, to the competitors, to ...' I don't know, 'somebody's mother or ...' Any excuse that was given, it was hysteria really because people were just frightened about it. And when we used to say like 'look, you know, people are doing this now, they can take a copy of something, they can email it to somebody, they can print a copy of, they can go round the corner, give it to somebody in a copy shop, why on earth should having a blog or a Wiki be a problem.""

We noticed that despite some initial reluctance to engage with social media, senior leaders quickly moved to adopt it, supported by the CEO who saw the use of social media, and more direct and open communication, as part of the new corporate strategy to maintain a sense of belonging while increasing staff mobility. Over time engaging with employees through social media became the norm and most senior management including the CEO were active in online forums and Q\&As. This shift in engagement is expressed by the following quote from a member of the intranet team:
"All the senior executives use it and are extremely visible. TRT's CEO has his own site. Every six weeks he does online chats, but also as an individual he behaves in certain ways that indicate he's on the intranet. For example, if he finds an error he tells someone. He also engages in some of the social media channels. TRT today has 'Your Views' and [CEO's name] has been known to go in and make his own comments. It's not his PA or some person in the communications department doing it for him. That's the same for all the lines of business CEOs. It's the kind of people we have here."

This focus on using the intranet and social media as a strategic driver for the business caused some tension initially with the competing demands from employees' interests and needs at the local level. Although they were interested in hearing from their leaders, they were also interested in sharing and communicating horizontally across the organization. Indeed, growth 
in adoption originated more from UGC services that allowed employees to communicate and share rather than from adding feedback features to established OPC services. The following quote by the Chief Editor of TRT's intranet shows this growth in the use of UGC services:

"We're seeing changes on Blog Central. Today, we have 450 blogs. 350 are active; 100 have limited activity. We've realized that blogging has moved well beyond enthusiasts and technologists. It's now used by 'normal' people. People want blogs for a wider range of reasons."

The tension between using social media as a strategic tool and local demands is also visible in the following quote:

"For social media there's not a common mindset. There are several collections of mindsets. In TRT there are enough early adopters to get momentum. Now we are at the 'here come the normal people' stage, people doing everyday jobs that have a need to communicate and find that social media is the most efficient way to do that in terms of benefit against effort."

We now show more clearly how these challenges and the responses to these challenges by the organization created new capabilities in the organization that allowed it to be more ambidextrous in its management of the two types of communication.

\section{Key findings: the making of communicational ambidexterity}

One of our main findings is that the growing use of social media and the expansion of UGC was not at the expense of centrally controlled and sanctioned OPC communication. Rather, our analysis demonstrated that UGC and OPC services were managed differently (see Table 1). For instance, services, such as TRT Today, TRT A-Z and TRT Directory strongly supported OPC, while services such as Blog Central and un-moderated discussion forums supported UGC. The growth of UGC as a much quicker and easier way to publish news and information attracted interest from site owners who felt that they could overcome the more robust and strict management of OPC by using UGC tools and services. The management team was concerned that this would compromise trust in the information provided to users, as it would be sanctioning information without appropriate oversight. One of the initiatives to address this concern was to create different colour schemes for each type of content. This segregation involved considerable effort and discussion. A wide range of issues from the choice of colours to categorisation of content indicate the significant effort in deliberately creating appropriate systems for two very different types of content and communication. Interestingly some UGC services were developed to respond to and complement OPC services. For instance YourViews with TRTToday and TRTpedia with TRTHelp. In this way, TRT was able to develop overtime the organizational ambidexterity capability that we had theorized. Evidence that this more participative mode of working was embedded in the way of working at TRT is visible in the following quote by a member of a local intranet team:

"The CEO blog and forum is an opportunity for two-way communication. For example, there was a discussion around a big change in the business and all the questions with senior leaders were posted online. This is a good way to involve employees." 
Next we consider the structural and contextual mechanisms that supported TRT's development of this capability to manage efficiently the conflicting demands from the two modes of communication.

\section{Enabling Mechanisms}

TRT came to realise that they needed to segregate the two types of communication and create separate governance structures to manage OPC and UGC services and content. We saw that TRT gradually developed the language and ontological map to separate these two types of communication, while simultaneously trying to create a consistent experience for users navigating across services and types of content. As TRT became more aware of the differences and created terms that allowed the communication of these differences it improved its ability to cope and use efficiently the two distinct modes of communication.

Another important mechanism contributing to the development of the communicational ambidexterity capability was the formal training of publishers to use OPC, but also creating online training packages for any employee interested in being more efficient in using the UGC tools. The two types of training perpetuated over time certain expected practices for each type of communication. An OPC publisher for example was required to comply with central guidelines, standards and security measures. By contrast, to publish using UGC tools no formal training was required, even though online training and guidelines were available. The governance principle for UGC was more about educating and supporting users, rather than controlling them. As one interviewee noted:

"We created a blog: 'bloggers helping bloggers' to crowd source. I did get a few responses. It's softer than rules, more like guidance. That's the sort of management you have to do in social media."

There were distinct dynamics of UGC communication and employees had to get used to a very different approach to using these services and tools. For example the Intranet manager humorously commented that when starting a blog "you'll get your fifteen minutes of fame because it will appear on the home page, but only till the next three have come along and removed it." He hinted that people adjusted to these new dynamics over time but that it was crucial to explain the shift in roles and expectation through training, policy and examples.

The ability to mentally shift from being passive receivers of OPC to participants in the UGC environment was another mechanism that helped in building the organization-wide capability in the new communicational environment. Creating this new mindset was achieved by constantly reminding people that "everyone is both a user and a publisher now." This is expressed in the following quote by a senior leader:

"The intranet is a key strategic enabler. It is about communicating with the employees. It is extensively used. It is not just a case of pushing pages. It's used to gain feedback, create new ways of working. It is very powerful tool to help set strategic direction."

A key mechanism in creating capabilities that enabled efficient management of both UGC and OPC was a shift in the communication culture of TRT. As explained earlier the emphasis on the use of social media was part of a wider process of transformation in the organization. One of the pillars of this strategy was to enable remote work through digital tools and the second was to change the culture of the company to encourage the behaviours that enabled 
the company to appropriate the new ways of working which relied on mobile work. To support this transformation TRT created a programme to promote four core new values for the organisation: "open", "inspiring", "straightforward" and "helpful".

Openness was an important value closely related to the adoption of social media. The organisation was keen to encourage employees to have a voice and share information and ideas in a more open and transparent environment. However they were also keen to highlight that with this power came responsibility and that all comments and views should be attributable to ensure that people do not misuse this opportunity. An interviewee in the internal communications department explained

"we're trying to engender a culture of free speech, in the sense that anyone can say what they want, not anonymously, and you are accountable for everything you say."

TRT was very serious in creating an "open" culture and added many features to encourage participation and interactivity. This came through in our interviews with users, for example one stated:

"We have a fairly popular blogging platform. Anyone can share opinions... Anyone can write in comments. Depending on the discussion, anyone, up to and including the CEO level, can get involved in providing views or add to the debate."

The second organizational value was to be "inspiring". This value was also closely related to the use of the new social media platform. It was an important driver for adoption and for producing great content and contributions. To be inspiring was key to ensure that the ideas shared would be relevant and important to the users. This was seen to address a concern shared in an internal review report that TRT's intranet has provided a platform to share knowledge and good practice, yet its strategic value for "encouraging, facilitating and showcasing innovation" was yet to be realised.

Another value encouraged within this new strategy was to be "straightforward". This value was promoted widely and incorporated in training manuals for all publishers responsible for OPC communication. Content and information had to be to the point and without unnecessary terminology. The significance of this for the use of social media within TRT is expressed in the quote below:

"We see evidence of the corporate values in people's actions; not just their words. For instance, people using the intranet are increasingly following TRT's value around being straightforward. We've cut out the long-winded, waffle-on articles. We've refined and reduced information down to key points. Blogging is quite illustrative as well. We don't do any moderation. It's a risky strategy, but people are professional and straightforward in putting their opinions forward."

The last value that contributed to a new culture of use of social media was to be "helpful". It referred to two aspects. On the one hand, it refers to the service orientation of TRT's intranet. For instance, two internal reports state the following as guiding principles for new developments: to "enhance user experience", "users find what they need", "information built around users' needs" and "users control information consumption". On the other hand, the 
other element strives to foster users' sense of ownership and shared responsibilities when communicating in TRT's intranet.

Our review above of the two types of mechanisms emerging from our analysis that fostered the capability to use and exploit OPC and UGC simultaneously show how this capability developed over time. Structural mechanisms operated by segregating formally the two modes of communication (OPC and UGC), initially through creating terms and names to distinguish them from each other and then by creating specific governance mechanisms for each type. Training was also an important structural mechanism that contributed to the developing communicational ambidextrous capability across the organisation. Finally, frequent reminders of the importance of shift in roles from passive readers to active contributors solidified a new approach, which promoted a new mindset in communication within TRT. The contextual mechanisms identified related to changes in the culture of the organization. Here we saw how the new values enabled TRT to appropriate the skills and ability to cope with the two distinct approaches to communication by promoting four new corporate values, closely linked to the use of social media. We review how each of these values of being "open", "inspiring", "straightforward" and "helpful" created the conditions that reinforced the intended behaviours of being both accurate and factual when producing and digesting OPC (straightforward and helpful) and simultaneously open and transparent linked to UGC ("open" and "inspiring"). These values contributed to creating the cultural context necessary for the effective use of the two modes of communication in TRT, so that employees engaged in online discussions for different purposes and were able to distinguish between rumours published by users (UGC) and facts checked by experts (OPC).

The following section outlines our theorisation of these findings, and further develops the notion of "communicational ambidexterity" in the making.

\section{Analysis and Discussion}

We now further develop the notion of "communicational ambidexterity in the making" to conceptualize the ongoing development of this distinctive capability which enabled TRT to simultaneously nurture univocality (associated with OPC) and multivocality (associated with UGC) by creating complementarity between these two distinct and potentially contradictory types of communication.

Our analysis suggests that a communicational ambidexterity capability involves the use and blending of new communication tools through establishing distinctive governance structures and a supportive organizational culture. We saw that the blending of these different dimensions in the day-to-day communication of employees (Cooren, et al., 2011) formed a distinctive form of communication, which enabled complementarity between univocality for OPC communication and multivocality for UGC communication. This contrasts with views in the literature that suggest that the opposing needs of each type of communication would prevent effective communication in the organization. As shown in the case, complementarity was reflected not just in how the two forms of communication co-existed well to form a balanced whole. For instance, how much communication space is devoted to each type of content so that users don't feel that the voice of the top management in OPC communication is too strong and over powering UGC communication. Equally important, complementarity is created as a distributed sense-making process (Cao, et al., 2009), based on gradual development of shared understanding and acceptance between users and managers of how to use diverse forms of communication in a more open and diverse communication environment. 
Another important analytical finding is the emergent nature of this new capability and the emphasis on this capability as a process rather than an outcome. "Communicational ambidexterity" was part of ongoing practices in the organization rather than being a property or an outcome. To be ambidextrous and cope with conflicting demands, as reflected in the case of TRT, required creating and recombining tools, governance structures, policies, culture and practices to effectively respond and adapt to new demands. We therefore suggest that this capability is "in the making". For instance, the engagement of users in debating, revising and, on some occasions, co-producing corporate strategic blueprints, formed vibrant, interactive and participative communication spaces which evolved alongside more formal spaces and content. For example the "Your Views" and Executive Q\&As encouraging user participation were closely linked to more formal sites and areas of the intranet published by central teams.

The above conditions underpin the development of "communicational ambidexterity" as a new organizational capability at TRT. Next we review the nature and characteristics of this new capability. We first review how the ability to architect the communication environment in a way that segregates the two types of communication played a role in forming different expectations for each type of communication. Secondly we review how the ability to formally regulate different types of communication played a role in creating a language that users were able to refer to when adopting the two types of communication. Thirdly we review how the ability to adapt organisational culture was also central in fostering the new capability. Finally, we present a model that reviews this capability and offers a process view of its development overtime leading eventually to an efficient and complementary use of distinct modes of communication within an organization.

\section{Architecting communication}

"Communicational ambidexterity" involved the ability to architect content and services in a way that set boundaries between opposing and distinct modes of communication. This ability was grounded in the possibilities afforded by the technical platform but also by creating new language and layout and colour coding to distinguish different needs of OPC or UGC communication. For instance, while blogging was mainly "conversational" and used to engage and exchange viewpoints, wiki-based tools were used for knowledge sharing and collaboration purposes. By contrast, "TRT Today" is the online news desk which is used to broadcast headlines from senior leaders. By incorporating different tools to address different communication needs, the underlying logic behind the architecture of TRT's communication platform mirrors the notion of "partitioning" (Adler, et al., 1999). In other words, each tool is used to enable and develop a rather distinctive space across the platform. By partitioning these spaces, different communication dynamics and processes can be individually catered for. In this way, multivocality can be concurrently developed alongside univocality. For instance, encouraging each user to embrace his/her 'voice' affords some of these communicational spaces to permit the principle of "multivocality" (Haslam, et al., 2003; McGriff, 2012). However, it does not mean that "univocality" - the voice from the organization (Balmer, 2001) -has to be compromised. Through partitioning, these two can be nurtured side-by-side. We suggest that the process and ability to partition TRT's communication platform according to different modes of communication was an important element in developing a new capability of "communicational ambidexterity".

\section{Governing communication}

Structurally separating each service/communicative space across the platform may not warrant sufficient synergy between them to develop complementary between univocality and 
multivocality. We saw that the ability to adjust governance of different types of communication by adjusting roles and expectations of use was an important mechanism to support effective use of the two modes of communication. What became evident is that the ability to change and adapt governance and policy was more important than the documents and roles established. Creating conditions for discussing and agreeing new ways to communicate and associated roles enabled the rebalancing of expectations.

\section{Dynamic culture of communication}

The ability to establish a value system that allows and supports communication based on OPC and UGC was an important aspect of our analysis. We found that TRT focused on changing culture of the organization at the same time as it deployed the tools and a large strategic move towards mobile working. Specifically, four distinctive yet interrelated corporate values, were promoted and nurtured by the central team as part of a large change project. This cultural shift was an important mechanism that supported the two types of communication. As illustrated in the case findings, these four corporate values include being "open", "inspiring", "straightforward" and "helpful". When comparing these corporate values with the four enabling mechanisms, in particular "trust" and "support", by Gibson and Birkinshaw (2004), the overlap in the emphasis of creating a collective and facilitating organizational context is clear.

These corporate values were a crucial mechanism to nurture and reinforce the growing democratization of internal communication, as reflected in the way TRT promoted user participation. However democracy does not mean the vacuum of power. Rather, it suggests different sources of power. In theory, power can be actualized virtually by everyone at TRT, because employees have all been given a voice. However, it is equally important to understand the specific contexts and communication spaces where such power/voice can be used, in particular in the context of UGC.

The above shows the mechanisms that underpin the new capability that we conceptualise as "communicational ambidexterity", that is constantly "in the making". Also, even though each mechanism provides its distinctive contribution to the development of communicational ambidexterity their influence has to be considered and developed integratively echoing the view of Jansen, et al. (2009). For instance, while the "architecting" might provide the structural definition and clarity to the users, the mechanism of "dynamic culture of communication" is crucial for creating an organizational context where both multivocality and univocality grow simultaneously. Simultaneously, "governing communication" is a core mechanism. The dual structure design, which includes central control and a user centric approach of governance provides the structure and orientation needed to reinforce the architecture of communication and the more dynamic culture. The governance mechanism is equally important for nurturing a communication culture and an organizational context by distributing the governance of TRT's internal communication among its users. This is well reflected in TRT's continuous efforts in promoting the shared ethos of 'ownership with responsibilities'. For instance, as stated in its social media policy, personal blogs can support the organization by "providing a mechanism for building communities through which the collective power of the community can solve problems and issues individuals face" and by "encouraging innovation and inspiring and engaging TRT colleagues."

\section{Stewardship as the outcome of communicational ambidexterity}

A concept that helps us to theorize how the enabling mechanisms worked together to support the development of the communicational ambidexterity capability at TRT is stewardship. 
Originally initiated to challenge the dominance of agency theory in the conceptualization of governance, the notion of stewardship refers to "situations in which managers are not motivated by individual goals, but rather are stewards whose motives are aligned with the objectives of their principals" (Davis, et al., 1997; p. 21). One of the underlying ethos of stewardship is a rejection of the traditional overgeneralization about "instrumentality" within corporations, providing in its place an alternative theoretical explanation in terms of how sustainability is achieved through the promotion of distinct psychological conditions (Hernandez, 2012). Despite its apparent appeal, how stewardship can potentially relate to the theorization of IT usage in general and social media enabled communication specifically remains largely unexplored. Also, despite the additional explanations by Davis, Schoorman and Donaldson which are well captured by two of the 'Dialogues' published in Academy of Management Review (Albanese, et al., 1997; Preston, 1998), later accounts have perceived stewardship and agency control as an "either-or" choice that a management team has to commit to. As Lewis (2000) and Sundaramurthy and Lewis (2003) point out, the either-or approach does not fully address the paradoxical nature of governance. According to both papers, control and collaboration need to be individually developed and enacted yet simultaneously orchestrated.

In TRT, different modes of communication, namely univocality and multivocality, were fostered by enabling mechanisms that allow a synthesis to emerge and this occurred as TRT employees became stewards of the intranet, as one user commented:

"As soon as something turns up on TRTpedia, there's an emerging behavior of wiki gardeners that tidy up. I don't know if there are techniques to encourage it, but it happened anyway."

Thus, an important part of TRT's ongoing effort was to promote the belief that 'TRT's intranet is for everyone and owned by everyone", therefore also looked after by everyone. The sense of stewardship not only encourages users to take initiative and share responsibilities, but also nurtures a different kind of mindset and behaviors. The efforts by TRT to separate different services, to develop effective governance mechanisms for each and to instil a collaborative culture, together helped to promote behaviors that take into account benefits of the collective rather than merely individuals. Stewardship, then, can be seen as the product of the communicational ambidexterity capability that had developed at TRT and was reflected in three types of behaviour: ownership, service orientation and self-regulation. Ownership relates to the need to update and maintain the OPC and UGC content, as well as aiming to foster users' sense of responsibility towards the way they use and engage via TRT's intranet. Service orientation is reflected mainly in the tendency to create content that can be shared and utilized across different parts of TRT, both in respect of UGC and OPC content. Self-regulation refers to how users form a community which co-creates its shared norms and functions, creating a governing body through rating and commenting on other members' and the organization's corporate postings. It is in these stewardship behaviors that we can see the complementarity between univocality and multivocality being enacted at TRT, and thus we describe stewardship as the performative outcome of the communicational ambidexterity capability developed (and continuing to develop) at TRT. Figure 3 below synthesises the main concepts covered above and captures the essence of our study. We believe that this framework could be a useful and powerful way to understand the complex dynamics of social media as a communicational platform within organizations. 


\title{
Figure 3. Proposed framework of communicational ambidexterity
}

\author{
$<$ Insert Figure 3 about here $>$
}

\section{Conclusion and Implications}

Our research examines the strategic use of social media as a distinct form of communication within organizations. We study the mechanisms needed for organizations to effectively use social media as a new communication platform. We conceptualise the new capability that can be produced as "communicational ambidexterity in the making", and we depict its characteristics, enabling mechanisms and the complementarity that can be achieved.

Our research effort is, however, more than merely an extension to the intellectual landscape of ambidexterity by theorizing and offering a new type of ambidexterity. It also attempts to further conceptualize internal communication as a constitutive process of organizing and organization (see, for example, Cooren, et al., 2011; Spee and Jarzabkowski, 2011; Taylor, 2011). By taking into account the role of IT in general and social media enabled communication more specifically, the concept of communicational ambidexterity provides the relevant theoretical explanation of how conflicting communicational challenges can be addressed to create complementarity in communicating simultaneously univocally and multivocally and that constitutes the essence of organizing.

While there is growing attention to ambidexterity in the IS research community, the emphasis has been mainly on the context of IT projects/products (e.g. Napier, et al., 2011; Tiwana, 2010; Vinekar, et al., 2006) and IT companies (Du, et al., 2013; Gulati and Puranam, 2009). Surprisingly, few have examined how IT enabled communication, in this case primarily via social media, can itself be considered an ambidextrous capability. In this regard, our account contributes to the IS literature with an integrative conceptual foundation to explain how strategic use of social media can provide valuable means to address conflicting communication challenges, and at the same time facilitate the development of complementarity between these challenges. Furthermore, despite growing interest on the strategic potential of social media, the focus is placed mainly on how organizations use it for external purposes, rather than for internal communication (Huang, et al., 2013; Majchrzak, et al., 2013). Our account represents an attempt to theorize this relatively vast yet underexplored terrain.

We are aware of the potential limitations of a single case study, in particular its ability for generalization (Denzin, 1997). Furthermore, even though the phenomenon of communicational ambidexterity is reported to represent the uniqueness of the case, we do not intend to project TRT's internal communication as completely unproblematic. Instead, we have outlined the importance of seeing communicational ambidexterity as something that is constantly in the making. Despite these limitations, our account has also yielded several valuable theoretical and practical contributions.

An important contribution of this study lies in the theorization of communicational ambidexterity by elaborating how univocality associated with OPC can be developed concurrently with multivocality associated with UGC through three different enabling mechanisms, namely architecting communication, governance structures and dynamic communication culture. Despite the newness of our offering, the notion of communicational ambidexterity draws on prior accounts of ambidexterity. For instance, the need to develop 
complementarity between conflicting activities pinpointed by Cao, et al. (2009) is well illustrated in how univocality and multivocality are developed and managed at TRT. Echoing several prior studies (e.g. Gulati and Puranam, 2009; Napier, et al., 2011; Tiwana, 2010), our findings also indicate the importance of using multiple mechanisms in order to foster ambidexterity, rather than the earlier conceptualizations of one type of mechanism (dual structures) fits all. Also, our account reinforces the view stressed by Jansen, et al. (2009) that different enabling mechanisms have to work in synchronization. Our data provides some insights on this phenomena and suggests that TRT developed a governance approach that enabled it to operate based on a centralised control governance model mainly designed to manage and maintain OPC, and simultaneously operate based on a decentralised system designed to support the publishing of UGC.

Our analysis of TRT's communicational environment also allowed us to theorise an emergent outcome of the development of communicational ambidexterity as stewardship (Sundaramurthy and Lewis, 2003), a concept that is rarely debated in the IS literature. Our account has elaborated not simply the role of stewardship and how it was developed as a product of the governance approaches adopted for different intranet services, but also how it was related to the nurturing of a participative, open and interactive communication culture. Even though theorizing stewardship is not our main research focus, we do believe that future studies can examine its relevance and implications for many different IS-related phenomena. Following the call for more practice-based studies by Whittington, R. (2014) we suggest that additional research on this topic may draw on the perspective of practice theory to examine how social media shapes and is shaped by the day-to-day taken-for-granted practices that it affords.

In addition to these theoretical contributions, our study also has managerial implications. With the growth of digital working and expansion of remote and mobile working arrangements, organizations face some shifts in the underlying processes of internal communication. New media affects patterns of communication. This then raises the issue of how social media can best be incorporated into the existing communicational landscape. Our findings suggest that the solution might lie in the concurrent development of multivocality and univocality through the enabling mechanisms outlined above. While the architecture of the communication platform and different governance policies can help organizations consider how different communication tools and spaces can be partitioned and integrated, the mechanism of communication culture can lead to the maturing of an organizational context where a diverse range of communication practices can be simultaneously enacted.

\section{References}

Adler, P., Goldoftas, B. and Levine, D. (1999) Flexibility versus efficiency? A case study of model changeovers in the Toyota production system. Organization Science 10: 43-68.

Agerdal-Hjermind, A. (2014) Organizational blogging: a case study of a corporate weblog from an employee perspective. Corporate Communications 19: 34-51.

Albanese, R., Dacin, M., Harris, IC., Davis, JH., Schoorman, FD. and Donaldson, L. (1997) Dialogue. Academy of Management Review 22: 609-613.

Andriole, SJ. 2010. "Business impact of Web 2.0 technologies." Communications of the ACM 53(12): 67-79.

Andriopoulos, C. and Lewis, MW. (2009) Exploitation-exploration tensions and organizational ambidexterity: Managing paradoxes of innovation. Organization Science 20(4), 696-717.

Balmer, J. (2001) Corporate identity, corporate branding and corporate marketing. European Journal 
of Marketing 35: 248-291.

Bartlett, CA. and Ghoshal, S. (1988) Organizing for worldwide effectiveness: The transnational solution. California Management Review 31: 54-74.

Beckman, CM. (2006) The influence of founding team company affiliations on firm behaviour. Academy of Management Journal 49: 741-758.

Boudreau, KJ. and Lakhani, KR. (2013) Using the crowd as an innovation partner. Harvard Business Review 91: 60-69.

Cao, Q., Gedajlovic, E. and Zhang, H. (2009) Unpacking organizational ambidexterity: Dimensions, contingencies, and synergistic effects. Organization Science 20: 781-796.

Carney, TF. (1972) Content analysis: A technique for systematic inference from communications, London: B.T. Batsford.

Champoux, V., Durgee, J. and McGlynn, L. (2012) Corporate Facebook pages: when "fans" attack. Journal of Business Strategy 33: 22-30.

Cook, S. (2008) The contribution revolution. Harvard Business Review 86: 60-69.

Cooren, F., Kuhn, T., Cornelissen, JP. and Clark, T. (2011) Communication, organizing and organization: An overview and introduction to the special issue. Organization Studies 32: 11491170 .

Davis, JH., Schoorman, FD. and Donaldson, L. (1997) Toward a stewardship theory of management. Academy of Management Review 22: 20-47.

Denyer, D., E. Parry, and P. Flowers. 2011. “'Social', 'Open' and 'Participative'? Exploring personal experiences and organizational effects of Enterprise 2.0 use." Long Range Planning 44:375396.

Denzin, NK. (1997) Interpretive ethnography: Ethnographic practices for the 21st century. Sage, Thousand Oaks, CA.

Du, WY., Pan, SL. and Zuo, MY. (2013) How to balance sustainability and profitability in technology organizations: An ambidextrous perspective. IEEE Transactions on Engineering Management 60: 366-385.

Duane, A. and Finnegan, P. (2003) Managing empowerment and control in an intranet environment. Information Systems Journal 13: 133-158.

Duncan, R. (1976) The ambidextrous organization: Designing dual structures for innovation. In Kilmann, R., Pondy, L., Slevin, D., (eds.), The Management of Organization. North-Holland, New York.

Easterby-Smith, M., Thorpe, R. and Lowe, A. (1991) Management research: An introduction. Sage, London.

Eisenhardt, KM. (1989) Building theories from case study research. Academy of Management Review 14: $532-550$.

Eisenhardt, KM. and Martin, JA. (2000) Dynamic capabilities: What are they? Strategic Management Journal 21: 1105-1121.

Fournier, S. and Avery, J. (2011) The uninvited brand. Business Horizons 54: 193-207.

Ghoshal, S. and Bartlett, CA. (1994) Linking organizational context and managerial action: The dimensions of quality in management. Strategic Management Journal 15: 209-226.

Gibson, CB. and Birkinshaw, J. (2004) The antecedents, consequences, and mediating role of organizational ambidexterity. Academy of Management Journal 47: 209-226.

Grant R. (1996) Prospering in dynamically-competitive environment: Organizational capability as knowledge integration. Organization Science 7: 375-387.

Gulati, R. and Puranam, P. (2009) Renewal through reorganization: The value of inconsistencies between formal and informal organization. Organization Science 20: 422-440.

Goh, KY., Heng, CS. and Lin, ZJ. (2013) Social media brand community and consumer behavior: Quantifying the relative impact of user- and marketer-generated content. Information Systems Research 24: 88-107.

Granados, N. and Gupta, A. (2013) Transparency strategy: Competing with information in a digital world. MIS Quarterly 37: 637-641.

Hall, R. and Lewis, S. (2014) Managing workplace bullying and social media policy: Implications for employee engagement. Academy of Business Research Journal 1: 128-138.

Hanna, R., Rohm, A. and Crittenden, V. (2011) We're all connected: The power of the social media 
ecosystem. Business Horizons 54: 265-273.

Haslam, SA., van Knippenberg, D., Platow, MJ. and Ellemers, N. (2003) Social identity at work: Developing theory for organizational practice. New York \& Hove, UK: Psychology Press.

He, XL. and Wong, PK. (2004) Exploration vs. exploitation: An empirical test of the ambidexterity hypothesis. Organization Science 15: 481-494.

Hernandez, M. (2008) Promoting stewardship behavior in organizations: A leadership model. Journal of Business Ethics 80: 121-128.

Hildebrand, C., Häubl, G., Herrmann, A. and Landwehr, JR. (2013) When social media can be bad for you: Community feedback stifles consumer creativity and reduces satisfaction with selfdesigned products. Information Systems Research 24: 14-29.

Huang, J., Baptista, J. and Galliers, RD. (2013) Reconceptualising rhetorical practices in organisations: The impact of social media on internal communications. Information \& Management 50: 112-124.

Jansen, J., Tempelaar, MP., van den Bosch, F. and Volberda, HW. (2009) Structural differentiation and ambidexterity: The mediating role of integration mechanisms Organization Science 20: 797-811.

Jarvenpaa, SL. and Majchrzak, A. (2010) Vigilant interaction in knowledge collaboration: Challenges of online user participation under ambivalence. Information Systems Research 21: 773-784.

Kang, SC. and Snell, SA. (2009) Intellectual capital architectures and ambidextrous learning: a framework for human resource management. Journal of Management Studies 46: 65-92.

Kaplan, A. and Haenlein, M. (2010) Users of the world, unite! The challenges and opportunities of social media. Business Horizons 53: 59-68.

Klein, H. and Myers, M. (1999) A set of principles for conducting and evaluating interpretive field studies in information systems. MIS Quarterly 23: 67-94.

Majchrzak, A., Wagner, C. and Yates, D. (2013) The impact of shaping on knowledge reuse for organizational improvement with wikis. MIS Quarterly 37: 455-481.

March, JG. (1991) Exploration and exploitation in organizational learning. Organization Science 2: 71-86.

Miles, SJ. and Mangold, WG. (2014) Employee voice: Untapped resource or social media time bomb? Business Horizons 57: 401-411.

Miller, AR. and Tucker, C. (2013) Active social media management: The case of health care. Information Systems Research 24: 52-70.

Napier, NP., Mathiassen, L. and Robey, D. (2011) Building contextual ambidexterity in a software company to improve firm-level coordination. European Journal of Information Systems 20: 674-690.

Newell, S., Scarbrough, H. and Swan, J. (2001) From global knowledge management to internal electronic fences: Contradictory outcomes of intranet development. British Journal of Management 12: 97-111.

Nicolini, D. (2007) Studying visual practices in construction. Building Research \& Information 35: 576-580.

Nicolini, D. (2012) Practice theory, work, and organization: An introduction. Oxford University Press, Oxford.

Oestreicher-Singer, G. and Zalmanson, L. (2013) Content or community? A digital business strategy for content providers in the social age. MIS Quarterly 37: 591-616.

Oh, O., Agrawal, M. and Rao, HR. (2013) Community intelligence and social media services: A rumor theoretic analysis of tweets during social crises. MIS Quarterly 37: 407-433.

Omilion-Hodges, LM. and Baker, CR. (2014) Everyday talk and convincing conversations: Utilizing strategic internal communication. Business Horizons 57: 435-445.

Orlikowski, WJ. (1993) CASE tools as organizational change: Investigating incremental and radical changes in systems development. MIS Quarterly 17: 309-340.

Orlikowski, WJ. (2000) Using technology and constituting structures: A practice Lens for studying technology in organizations. Organization Science 11: 404-428.

Pan, SL. and Tan, B. (2011) Demystifying case research: A structured-pragmatic-situational (SPS) approach to conducting case studies. Information and Organization 21: 161-176.

Pitt, L. and Berthon, P. (2010) Just when you thought it was safe to go back into the Web: Marketing 
meets Web 2.0, social media, and creative customers. Business Horizons 54: 181-183.

Preston, LE., Wright, TA., Larwood, L. and Mowday, RT. (1998) Dialogue. Academy of Management Review 23: 9-13.

Raisch, S. and Birkinshaw, J. (2008) Organizational ambidexterity: Antecedents, outcomes, and moderators. Journal of Management 34: 375-409.

Schatzki, T.R., 2001. Introduction: practice theory. In Schatzki, T.R., Knorr-Cetina, K., von Savigny, E., (eds.), The Practice Turn in Contemporary Theory. Routledge, London.

Skågeby, J. (2010) Gift-giving as a conceptual framework: framing social behavior in online networks. Journal of Information Technology 25: 170-177.

Smith, WK. and Tushman, ML. (2005) Managing strategic contradictions: A top management model for managing innovation streams. Organization Science 16: 522-536.

Spee, AP. and Jarzabkowski, P. (2011) Strategic planning as communicative process. Organization Studies 32: 1217-1245.

Sundaramurthy, C. and Lewis, M. (2003) Control and collaboration: Paradoxes of governance. Academy of Management Review 28: 397-415.

Subramaniam, N., J. Nandhakumar and J. Baptista (2013) Exploring Social Network Interactions in Enterprise Systems: The Role of Virtual Co-Presence Information Systems Journal, 23 (5)

Taylor, JR. (2011) Organization as an (imbricated) configuring of transactions. Organization Studies 32: 1273-1294.

Tiwana, A. (2010) Systems development ambidexterity: Explaining the complementary and substitutive roles of formal and informal Controls. Journal of Management Information Systems 27: 87-126.

Tushman, ML. and O'Reilly, C. (1996) Ambidextrous organizations: Managing evolutionary and revolutionary change. California Management Review 38: 8-30.

Väyrynen, K., R. Hekkala, and T. Liias. 2013. "Knowledge protection challenges of social media encountered by organizations." Journal of Organizational Computing and Electronic Commerce 23: 34-55.

Vinekar, V., Slinkman, CW. and Nerur, S. (2006) Can agile and traditional systems development approaches coexist? An ambidextrous view. Information Systems Management 23: 31-42.

Walsham, G. (1995) Interpretive case studies in IS research: Nature and method. European Journal of Information Systems 4: 74-81.

Whittington, R. (2014) Information Systems Strategy and Strategy-as-Practice: A Joint Agenda The Journal of Strategic Information Systems (23:1), pp. 87-91

Wu, L. (2013) Social network effects on productivity and job security: Evidence from the adoption of a social networking tool. Information Systems Research 24: 30-51.

Yuan, Y., Zhao, X., Liao, Q. and Chi, C. (2013) The use of different information and communication technologies to support knowledge sharing in organizations: From e-mail to micro-blogging. Journal of the American Society for Information Science \& Technology 64: 1659-1670. 
Figure 1. An integrative framework of ambidexterity and its enabling mechanisms

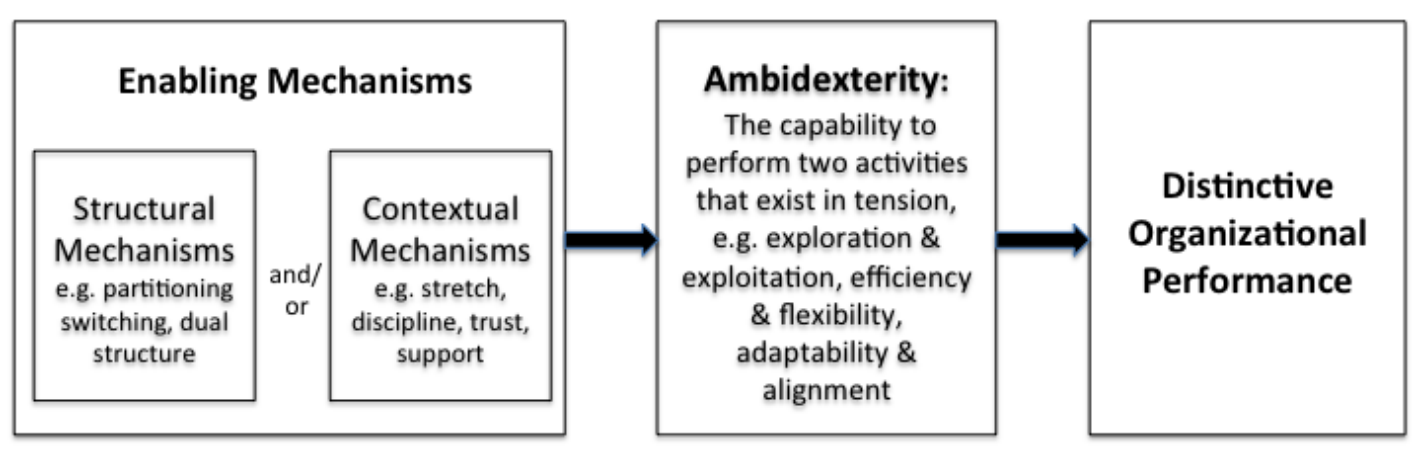

Figure 2. A chronological view of key events and communication challenges

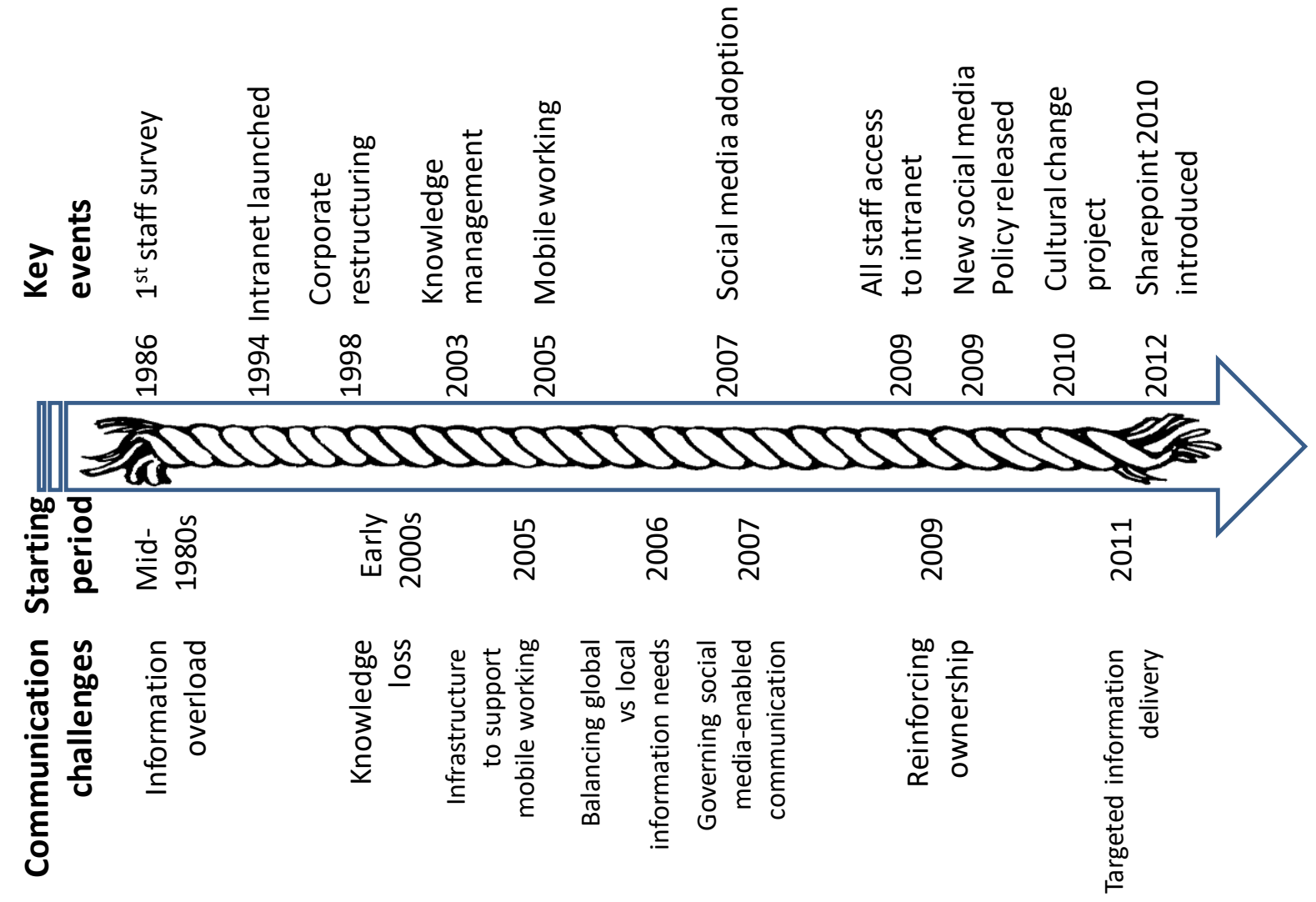


Figure 3. Proposed framework of communicational ambidexterity

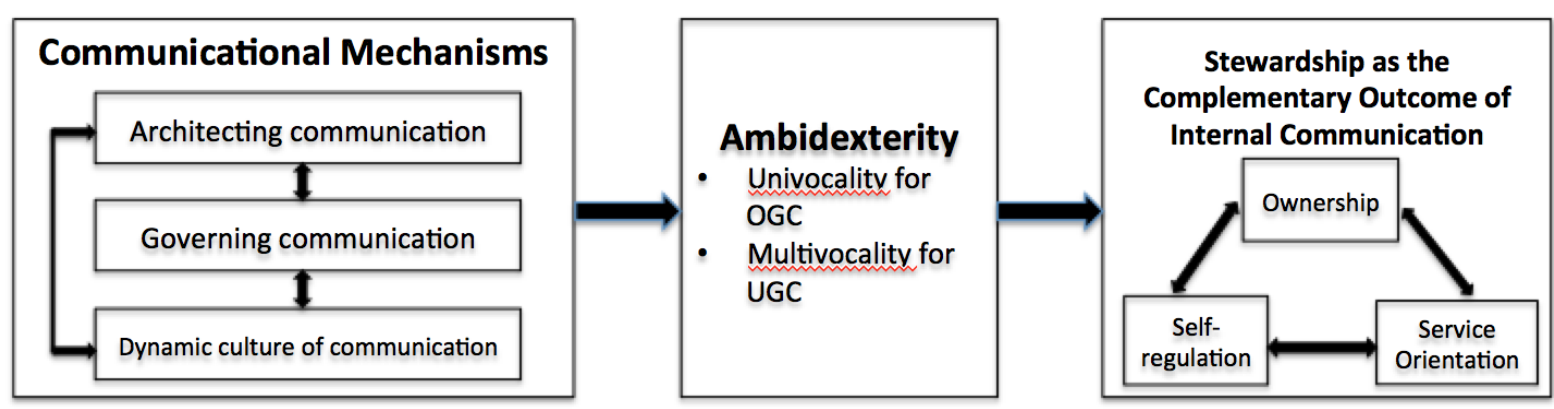


Table 1. Intranet services, functions, governance \& content management and usage description

\begin{tabular}{|c|c|c|c|c|}
\hline Categories & Services & Functions & Governance \& content management & Usage description \\
\hline \multirow[t]{6}{*}{$\begin{array}{l}\text { Organization- } \\
\text { published } \\
\text { content }(\text { OPC) } \\
\text { channels }\end{array}$} & $\begin{array}{l}\text { Intranet } \\
\text { homepage }\end{array}$ & $\begin{array}{l}\text { Provide headline news to staff and } \\
\text { serve as a gateway to most needed tools } \\
\text { and resources within TRT }\end{array}$ & $\begin{array}{l}\text { Managed by the Intranet Team in conjunction with } \\
\text { Internal Communications under tight control to ensure } \\
\text { relevance and usefulness of the homepage for all } \\
\text { employees }\end{array}$ & $\begin{array}{l}\text { By policy all employees were expected to access } \\
\text { the intranet and the homepage was the default } \\
\text { page for all devices uses by employees to access } \\
\text { the intranet. TRT eliminated other } \\
\text { communication channels so employees had to } \\
\text { stay up-to-date by regularly consulting the } \\
\text { homepage }\end{array}$ \\
\hline & TRT Today & $\begin{array}{l}\text { This is a newsroom channel to keep } \\
\text { employees up to date with changes to } \\
\text { the business and organisation. Played a } \\
\text { key role in culture building. }\end{array}$ & $\begin{array}{l}\text { Managed by a small team of editors within Internal } \\
\text { Communications centrally but relying also on editors at } \\
\text { the local level to escalate stories to the central team to } \\
\text { keep this channel balanced and with an appropriate mix } \\
\text { of both global and local content. }\end{array}$ & $\begin{array}{l}\text { The news channel was extremely popular across } \\
\text { TRT with most employees consulting it at least } \\
\text { once a week. }\end{array}$ \\
\hline & $\begin{array}{l}\text { Staff } \\
\text { Directory }\end{array}$ & $\begin{array}{l}\text { The directory played a key role in TRT } \\
\text { in connecting staff across the many } \\
\text { areas of TRT. }\end{array}$ & $\begin{array}{l}\text { Managed centrally by HR with a tight control for the } \\
\text { main elements of the profile of employees but then users } \\
\text { were encouraged to add richer information about their } \\
\text { interests and projects as well as expertise and other } \\
\text { searchable meta data about them. }\end{array}$ & $\begin{array}{l}\text { This service was used daily by many employees } \\
\text { to find colleagues. It was always one of the top } \\
\text { tasks in usability testing. }\end{array}$ \\
\hline & $\begin{array}{l}\text { TRT } \\
\text { Services }\end{array}$ & $\begin{array}{l}\text { A large number of applications and } \\
\text { links to services that ranged from check } \\
\text { payslips to holiday booking to arrange } \\
\text { travel and procurement and booking } \\
\text { rooms and equipment for meetings }\end{array}$ & $\begin{array}{l}\text { The provision of these services depended on the } \\
\text { integration with IT systems and in-house development } \\
\text { managed by the IT team but coordinated by the central } \\
\text { intranet team in terms of the overall user guidelines of the } \\
\text { intranet }\end{array}$ & $\begin{array}{l}\text { These services were used everyday by many staff } \\
\text { to do their jobs. Most employees worked } \\
\text { remotely or mobile so this allowed them to } \\
\text { perform their daily jobs without having to } \\
\text { physically attend offices or call people over the } \\
\text { telephone. }\end{array}$ \\
\hline & $\begin{array}{l}\text { Search } \\
\text { engine and } \\
\text { AtoZ }\end{array}$ & $\begin{array}{l}\text { The search function and the AtoZ } \\
\text { played a major role in providing the } \\
\text { necessary structure to ensure that users } \\
\text { could find the information that they } \\
\text { needed }\end{array}$ & $\begin{array}{l}\text { The AtoZ and the search results were managed tightly by } \\
\text { the central Intranet Team who conducted regular user } \\
\text { testing and used logs to fine-tune and improve results }\end{array}$ & $\begin{array}{l}\text { Search and AtoZ were very popular and used } \\
\text { regularly by most users as a way to navigate all } \\
\text { the areas of the intranet. }\end{array}$ \\
\hline & $\begin{array}{l}\text { Forms } \\
\text { central }\end{array}$ & $\begin{array}{l}\text { A repository of official documents and } \\
\text { forms where employees could find the } \\
\text { most up to date version of important } \\
\text { documents }\end{array}$ & $\begin{array}{l}\text { Managed by specific editors in each line of business } \\
\text { following specific guidelines and workflow within the } \\
\text { system to ensure that documents published were checked } \\
\text { and compliant with guidelines }\end{array}$ & $\begin{array}{l}\text { This was not the most popular service but crucial } \\
\text { when employees needed accurate information for } \\
\text { prompt decision making. }\end{array}$ \\
\hline User-generated & TRTpedia & This is a list of acronyms showing the & The system relied on employees contributing and & This was a very popular service especially for \\
\hline
\end{tabular}




\begin{tabular}{|c|c|c|c|c|}
\hline \multirow[t]{5}{*}{$\begin{array}{l}\text { content (UGC) } \\
\text { services }\end{array}$} & & $\begin{array}{l}\text { definition of key terms used within } \\
\text { TRT to help new recruits get up to } \\
\text { speed with all the lingo used within the } \\
\text { organization. }\end{array}$ & $\begin{array}{l}\text { maintaining information and was fully editable by any } \\
\text { employee. The central team managed the infrastructure } \\
\text { and delivery of the service but not the content apart from } \\
\text { when they themselves contributed with their own terms }\end{array}$ & $\begin{array}{l}\text { new employees. It was like an encyclopaedia so } \\
\text { more used on a need-to-use basis. }\end{array}$ \\
\hline & $\begin{array}{l}\text { Blog } \\
\text { Central }\end{array}$ & $\begin{array}{l}\text { A blog platform for individual } \\
\text { employees to publish information and } \\
\text { share information with colleagues } \\
\text { across TRT }\end{array}$ & $\begin{array}{l}\text { Each individual was required to accept terms and } \\
\text { conditions before being given permission to blog but } \\
\text { there was no central control of checks afterwards by the } \\
\text { central team }\end{array}$ & $\begin{array}{l}\text { The number of blogs grew initially but then } \\
\text { stabilised. There were some very popular blogs } \\
\text { mostly by senior executives but also by technical } \\
\text { experts that provided useful information to } \\
\text { colleagues such as a blog focused on the use of } \\
\text { Blackberries }\end{array}$ \\
\hline & $\begin{array}{l}\text { Executive } \\
\text { Q\&As }\end{array}$ & $\begin{array}{l}\text { Biweekly online session where the } \\
\text { CEO responded to any question from } \\
\text { employees through an online chat } \\
\text { platform }\end{array}$ & $\begin{array}{l}\text { The questions were from any employee and the answers } \\
\text { were also given on the spot by the CEO }\end{array}$ & $\begin{array}{l}\text { This was extremely popular and most employees } \\
\text { in TRT followed this service very closely }\end{array}$ \\
\hline & $\begin{array}{l}\text { Your } \\
\text { Views }\end{array}$ & $\begin{array}{l}\text { This section within TRT Today allowed } \\
\text { employees to comment on news in a } \\
\text { discussion forum style }\end{array}$ & $\begin{array}{l}\text { The comments and contributions were posted openly and } \\
\text { in a very open tone of voice, with no direct management } \\
\text { by the central team. }\end{array}$ & $\begin{array}{l}\text { This was a popular service that had some very } \\
\text { regular and strong followers }\end{array}$ \\
\hline & MySites & $\begin{array}{l}\text { This platform supports collaboration } \\
\text { and team work. }\end{array}$ & $\begin{array}{l}\text { Anyone can start a new team site and use it to collaborate } \\
\text { and share information and documents with no } \\
\text { intervention from a central team }\end{array}$ & $\begin{array}{l}\text { There was an explosion in the adoption of team } \\
\text { sites and quickly became a very popular platform } \\
\text { for teams to share documents and information } \\
\text { within TRT }\end{array}$ \\
\hline
\end{tabular}

